\title{
The false dichotomy: a refutation of the Neandertal indistinguishability claim
}

\section{Thomas Wynn ${ }^{1,2}$, Karenleigh A. Overmann ${ }^{1,3}$ \& Frederick L. Coolidge F,4 $^{1,4}$}

1) The Center for Cognitive Archaeology, University of Colorado, Colorado Springs, 1420 Austin Bluffs Pkwy, Colorado Springs, CO 80918 USA

2) Department of Anthropology, University of Colorado, Colorado Springs, 1420 Austin Bluffs Pkwy, Colorado Springs, CO 80918 USA

3) Keble College, Parks Road, University of Oxford, Oxford, England, OX1 3PG, UK

4) Department of Psychology, University of Colorado, Colorado Springs, 1420 Austin Bluffs Pkwy, Colorado Springs, CO 80918 USA

e-mail: fcoolidg@uccs.edu

Summary - In the debate about the demise of the Neandertal, several scholars have claimed that humanity's nearest relatives were indistinguishable archaeologically, and thus behaviorally and cognitively, from contemporaneous Homo sapiens. They suggest that to hold otherwise is to characterize Neandertals as inferior to $\mathrm{H}$. sapiens, a false dichotomy that excludes the possibility that the two human types simply differed in ways visible to natural selection, including their cognition. Support of the Neandertal indistinguishability claim requires ignoring the cranial differences between the two human types, which have implications for cognition and behavior. Further, support of the claim requires minimizing asymmetries in the quantity and degree of behavioral differences as attested by the archaeological record. The present paper reviews the evidence for cognitive and archaeological differences between the two human types in support of the excluded middle position.

Keywords - Neandertals, Encephalization, Globularization, Cognitive Evolution.

\section{Introduction}

The discovery of the first Neandertal fossil in 1856 initiated a seemingly endless debate concerning its status. Should Neandertals be considered a different species, as exemplified by William King's 1864 proposal for Homo neanderthalensis, or should they be counted as a subspecies of Homo sapiens? Lurking beneath this debate have been two apparently incompatible interpretations of Neandertal behavior, with one extreme painting a picture of brutish simplicity, and the other presenting Neandertals as indistinguishable from modern humans. This disagreement has hinged on the relative absence of more sophisticated archaeological artifacts and behaviors like parietal art, stylized figurines, and highly ritualized burials among Neandertal archaeological remains. Was this evidence for cognitive differences, or was the absence of these behaviors merely an artifice of deposition and discovery? It is undoubtedly the case that, especially in the late $19^{\text {th }}$ and early $20^{\text {th }}$ centuries, the Neandertals were considered inferior and portrayed as rather brutish cave dwellers. Today, not only has the pendulum swung in the opposite direction, it shows signs of becoming stuck at the far extreme, in which Neandertals appear just like us. This is the Neandertal indistinguishability claim. Even the demise of the Neandertals has been contentious, with various sides claiming that 
it was just a simple quirk of fate ("there but for the grace of God go we"), contemporaneous $H$. sapiens were in direct competition and killed the Neandertals off in some fashion, the Neandertals' own behavior contained the seeds of their demise, or the Neandertals were simply assimilated into the H. sapiens' population.

Recently, Villa \& Roebroeks (2014) and Zilhão (2014) have further inflamed the debate by claiming that the Neandertals were archaeologically - and thus behaviorally and cognitively - indistinguishable from contemporaneous $H$. sapiens. They represent the opposition to this position starkly: Those who support it believe Neandertals were inferior, $H$. sapiens superior, because they are afflicted by "a persistent, if subconscious influence ... of Victorian-age ideas of evolution-as-progress and ancient-as-primitive" (Zilhão, 2014). It is our present contention that they are creating a false dichotomy by excluding a middle position that holds Neandertals and $H$. sapiens were simply different from each other in ways visible to natural selection. The middle position also presupposes that the differences between the two human types made neither one better or worse than the other (e.g., Langbroek, 2012; Mithen, 2014). As Mithen astutely observed, differences in the "cognitive characteristics" of Neandertals and H. sapiens are "entirely unrelated to making value judgments" about them (p. 8).

As Wynn \& Coolidge noted in 2004:

"Neandertals did compete on a par with anatomically modern humans for thousands of years and may even have out-competed them for several millennia in the Levant (Arsuaga, 2001; Shea, 2003). Had [Neandertals] possessed a dramatically less powerful intelligence, this situation is unlikely to have occurred. Comparisons of Neandertal and modern behavior have tended either to overemphasize the differences (Binford, 1981) or overemphasize the similarities (d'Errico et al., 1998). A more appropriate solution is to posit a small cognitive difference that had profound long-term consequences" (Wynn o Coolidge, 2004, p. 468).
What Wynn \& Coolidge proposed then is likely true now: It is possible that a small but significant difference in cognition, like workingmemory capacity or executive functions, made the difference in the respective fates of the two human species.

A corollary to the null hypothesis of the false dichotomy is the idea that Neandertal indistinguishability can only be rejected by "distortions of method and logic" and "double standards in the assessment of the evidence" (Zilhão, 2014). This is an ironic stance for indistinguishability proponents to assume for two reasons: First, support of Neandertal indistinguishability requires ignoring the cognitive implications of the cranial differences between the two human types; second, it requires minimizing asymmetries in the quantity and degree of behavioral differences as attested by the archaeological record. The present paper reviews the evidence for cognitive and archaeological differences between the two human types to support the middle position excluded by Villa \& Roebroeks (2014) and Zilhão (2014): Neandertals and early or anatomically modern humans (AMH) differed cognitively in ways subject to natural selection. Such differences are, after all, what natural selection acts upon, even when they are subtle.

\section{On the relationship between neuroanatomy and cognitive functions}

Paleoanthropology has long recognized that the fossil crania of Neandertals and AMH differ in both size and shape. Cognitive science has long accepted the observations that cranial size and shape are produced by (and are thus related to) brain growth and development and that neuroanatomy and cognitive functioning are related. Do size and shape matter? The answer is yes: neuroanatomical differences in the size and shape of Neandertals and AMH fossil crania are important because they have implications for cognitive functioning. 


\section{Brain size matters}

Neandertal brains were generally about $10 \%$ larger than those of AMH (e.g., Holloway et al., 2009; Martin, 1984; but also see Rightmire, 2004; Stanyon et al., 1993). If the 10\% increase in size included a $10 \%$ increase in number of neurons (far from certain), then theoretically there might have been an increase in processing power. Increases in brain size in hominin evolution were often accompanied by increases in cultural complexity. This larger size could also have been disadvantageous; greater brain size would have increased Neandertal daily caloric requirements above those of AMH because brain tissue is metabolically expensive and bigger brains need more calories than smaller ones do. Greater brain size also might have made Neandertal brains slightly more subject to the evolutionary trade-offs associated with encephalization than AMH brains may have been, including susceptibility to metabolic heat and disease (Bruner, 2014; Bruner et al., 2014) and reduction in interregional brain connectivity and the number of neurons (Azevedo et al., 2009; Kaas, 2000). Bruner (2014) has further speculated that the Neandertal brain "may have reached some structural limits in [its] neurocranial organization" (p. 125), an interpretation based on the principles of cranial development and features of Neandertal crania (e.g., ossification patterns).

As the larger Neandertal brain was related to the larger Neandertal body, Pearce et al. (2013) have argued that Neandertal brains would likely have "invested more neural tissue in somatic areas involved in body maintenance and control compared with those of contemporary AMHs" (p. 5). In comparison, the smaller AMH brain size was related to its more globular shape (a consequence of parietal encephalization in $\mathrm{AMH}$ but not Neandertals, discussed later), giving $\mathrm{AMH}$ a slightly higher Encephalization Quotient (an allometric ratio of actual to predicted brain size that takes body mass into account) because of their reduction of brain and body size relative to Neandertals, while concomitantly reducing their caloric requirements (Hublin et al., 2015). Further, "Neanderthal brains grew differently early in ontogeny, and probably prenatally, when compared with modern humans" (Bastir et al., 2011, p. 5). The latter difference may have had implications for caloric requirements for Neandertals, especially in early childhood.

\section{Brain shape matters too}

The differences in the gross neuroanatomical shape also have important implications for cognitive functioning. The most demonstrable differences in the neuroanatomy of the two human types are found in the relative sizes of certain gross anatomical structures. AMH had relatively larger parietal lobes (Bruner, 2004; Bruner et al., 2003), larger temporal lobe poles (Hublin et al., 2015), wider orbitofrontal cortex (Bastir et al., 2008), larger olfactory bulbs (Bastir et al., 2011), larger cerebellums (Weaver, 2005; Hublin et al., 2015), and relatively smaller occipital lobes than Neandertals (Pearce et al., 2013).

Parietal expansion is perhaps the single characteristic that best distinguishes $\mathrm{AMH}$ brains from the brains of all other primates, including the Neandertals, whose brains appear to have a less derived morphology, including parietal size and shape (Bruner et al., 2003). Parietal expansion in $\mathrm{AMH}$ gave the brain a rounder, more globularized cranial shape (Bruner, 2010; Bruner et al., 2003, 2004; also see Fig. 1, right). These bulging parietals may have been linked to neural reorganization of component structures such as the precuneus, intraparietal sulcus, surpramarginal gyrus, and angular gyrus (e.g., Bruner et al., 2014, 2015; Coolidge, 2014; Hublin et al., 2015). By comparison, Neandertals' parietal expansion occurred laterally, yielding the diagnostic 'en bombe' shape to their crania (Bruner, 2014; also see Fig. 1, left). Relative to AMH brains, Neandertal brains were longer from front to back, wider from side to side, and flatter at the top above the parietal region.

\section{Brain developmental trajectories matter as well}

Bruner $(2004,2010)$ noted that Neandertals may have had different phylogenetic and ontogenetic brain trajectories than AMH. While Neandertals and AMH shared a common frontal 


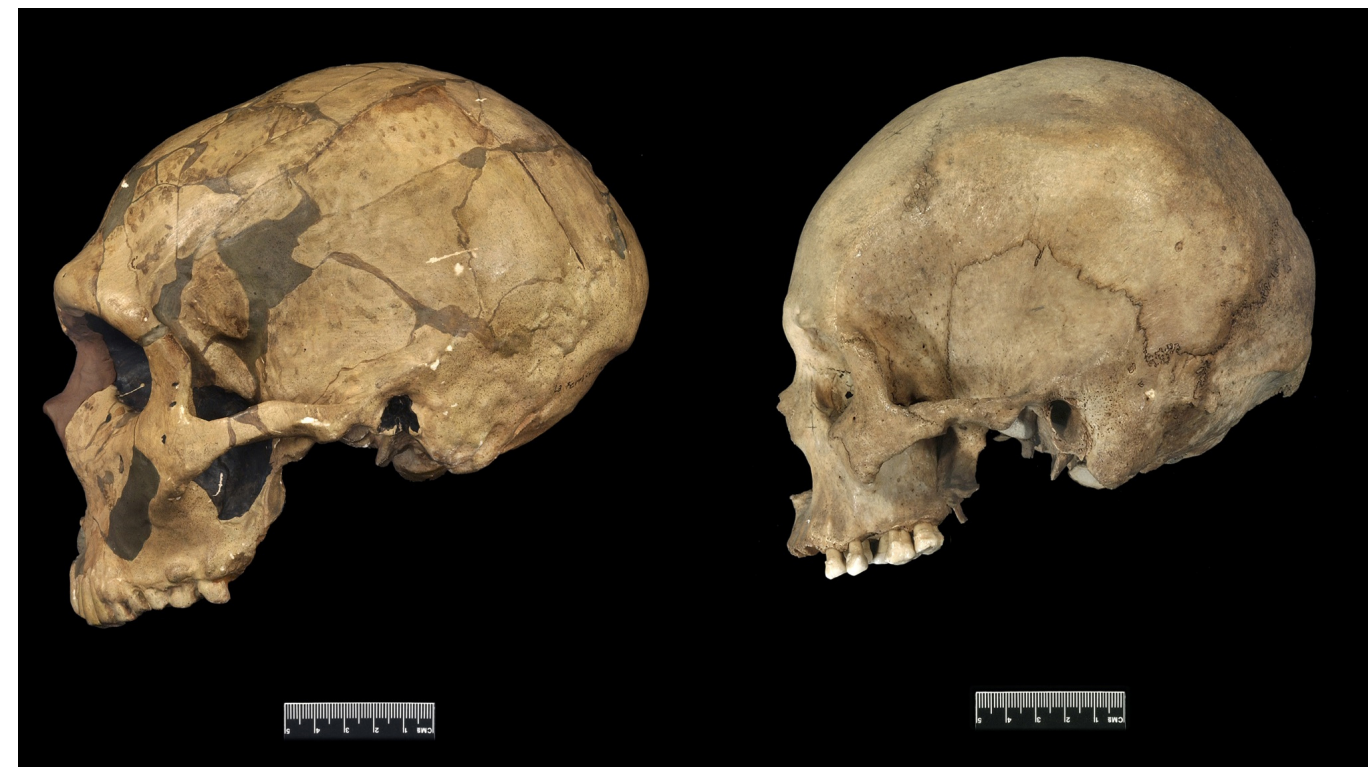

Fig. 1 -Neandertal (cast of La Ferrassie 1, left) and H. sapiens (modern human, right) cranial differences. Image courtesy of Chris Stringer. Reproduced with permission of Chris Stringer/Natural History Museum London. The colour version of this figure is available at the JASs website.

lobe and general cerebral expansion that differentiated both from earlier Homo (Ponce de León \& Zollikofer, 2001), Bruner and colleagues (e.g., Bruner et al., 2003) found that AMH and Neandertals followed different expansion trajectories. Bastir et al. (2011) also concluded that there were different evolutionary trajectories between the two human types as well, particularly for olfactory systems (as will be discussed shortly) and basal and temporal poles. Pearce et al. (2013) have also hypothesized that the Neandertal evolutionary brain trajectory was more invested in visual and somatic systems and retained the earlier physical robustness of the likely common ancestor of both human types, Homo heidelbergensis. Regarding development, Gunz et al. (2010) have demonstrated that Neandertal brains had a different ontogenetic growth pattern than $\mathrm{AMH}$, and that there was likely a different prenatal brain growth pattern as well. Sasaki et al. (2002) suggested that Neandertal infants had faster skeletal growth patterns, and Hublin et al. (2015) have suggested faster dental development pattern in Neandertals.
The impact of parietal expansion on AMH brains

Globularization of the AMH brain may have decreased inter-regional connectivity, shortening the long connections between brain regions, and consolidated intra-regional connections, increasing within-region connectivity (Rilling $\&$ Insel, 1999). Shorter, denser pathways are faster (Gibson \& Petersen, 1991; Gibson, 1991) and more efficient in larger brains, which generally "reduce the proportion of connections, especially the most costly long connections" as a consequence of encephalization (Kaas, 2000, p. 17). This trade-off perhaps explains the limited interhemispheric connectivity in extant $H$. sapiens; as a percentage of total brain volume, the human corpus callosum is half or a third of that of other primates (Preuss et al., 2002). Globularization was perhaps also a factor in avoiding another potential consequence of encephalization, the reduction in the number of neurons (Kaas, 2000). The number of human neurons has remained isometrically proportional to the number found in other primate brains (Azevedo et al., 2009), despite encephalization. The evolutionary trade-offs 
imply that Neandertal brains, which lacked such globularization, may have also lacked its attendant mitigation of encephalization-related issues of connectivity and neuronal numbers.

\section{Parietal lobe functions}

Research, especially within the past five years, has implicated the parietal lobe in a number of critical cognitive functions (e.g., Coolidge, 2014), including visuospatial working memory (Koenigs et al., 2009), the creation of inner space' representations of external space (Land, 2014), the abilities to grasp and manipulate objects like tools and understand cause-effect relations in tool use (Orban \& Caruana, 2014), and the sense of self, self-representation, and self-consciousness (Cavanna \& Trimble, 2006; Lou et al., 2004). An inner lateral portion of the parietal lobe, the intraparietal sulcus, has been implicated in quantity appreciation and number processing (see Coolidge \& Overmann, 2012 for a review), and the topographical representation of number in the intraparietal sulcus may aid higher cognitive functions like abstraction (Harvey et al., 2013). Recent imaging studies (fMRI) have shown that a medial and deep portion of the parietal lobes, the precuneus, may be critical to egocentric memory, the ability to create internal, stable representations of the external environment and one's place within it (Land, 2014). The precuneus has also been implicated in critical higher-order cognitive tasks, including the integration of visuospatial imagery, retrieval of episodic and autobiographical memories, and ability to take first-person perspectives in the experience of agency (Allen \& Fortin, 2013; Cavanna \& Trimble, 2006). Recently, Bruner \& Iriki (2015) suggested that differences in brain morphology between Neandertals and AMH, particularly the upper and medial parietal lobe areas (i.e., precuneus, intraparietal sulcus), may have resulted in different ways of interfacing the environment with internal representations.

Two additional critical higher-order cognitive functions have been shown to be controlled by the parietal lobes: One is autonoetic thinking, the ability to recognize that the awareness of time is subjective, that one may travel backward and forward in it and, thus, that time may be perceived as relative (Tulving, 2002). The second critical function is prospective memory and future memory simulation (Addis et al., 2007; Schacter \& Addis, 2007).

Poles

Compared to Neandertals, AMH had larger frontal and temporal poles, which are the anterior ends of the frontal and temporal lobes (Bastir et al., 2011; Hublin et al., 2015). Greater asymmetry in the frontal and temporal poles is important because it is indicative of lateralization, the functional division of labor between the two cerebral hemispheres that informs and underlies computationally expensive processes such as language.

\section{Orbitofrontal cortex}

Hublin et al. (2015) have noted a wider orbitofrontal cortex in AMH than Neandertals. Modern empirical studies of extant humans have long demonstrated the importance of the prefrontal cortex (PFC) to higher level cognitive functions such as behavioral and social/emotional regulation, abstraction, theory of mind, and many others (e.g., Gazzaninga et al., 2013). However, the PFC is not cellularly homogenous, as it has been shown that the dorsolateral (DL) PFC is closely interconnected to the primary sensory and motor regions, and the parietal lobes, while the orbitofrontal (OF) PFC is intimately connected to the limbic system. The arcuate fasciculus, a bundle of communication neurons, connects both the DLPFC and OFPFC to the superior posterior portion of the temporal lobes, the latter of which is the critical area for essential language functioning. The OFPFC has long received particular attention for its role in social and emotional decision-making (e.g., Bechara et al., 2000). The OFPFC has also been recognized for its critical role in inhibiting responses, representing specific stimulus-outcome associations, guiding behavior by signaling emotional markers, predicting errors and assigning them to appropriate causes, and inferring value in economic determinations (Stalnaker et al., 2015). 


\section{Olfactory bulbs}

Bastir et al. (2011) have noted that cribriform plate, which connects the olfactory epithelium in the nasal cavity to the olfactory bulbs, appears to have expanded posteriorly and is larger in AMH compared to Neandertals. As the cribriform plate is highly correlated with the size of the olfactory bulbs, they surmised that the latter may also have been larger in AMH. It has long been recognized evolutionarily that forebrain expansion was driven by olfaction and the latter's critical role in approach functions related to feeding and reproduction, as well as avoidance functions such as predator detection and escape. Strous \& Shoenfeld (2006) have shown that olfaction is intimately linked to the immunological system, which may be important in female's mate selection, with possible positive implications for improved immunological fitness of their progeny (also see Lübke \& Pause, 2015).

\section{Cerebellum}

AMH "displayed a proportionally larger cerebellum than Neandertals" (Hublin et al., 2015, p. 6), a consequence of the different evolutionary trajectories of the base of the brains of the two human types. Weaver (2005) also had earlier suggested that AMH had a larger cerebellar quotient (cerebellum volume to whole brain volume) than Neandertals. Kubo and colleagues (Kubo et al., 2014) have recently confirmed that there is a high correlation $(r=.88)$ between the size of posterior cranial fossa of extant skulls and cerebellar volume, a finding that should be extensible to fossil crania.

The cerebellum, which is widely interconnected with every major region of every lobe of the brain (e.g., Balsters et al., 2013), has traditionally been associated with motor learning, fine motor control, and motoric action sequencing. There are highly reciprocal neural connections between the cerebellum and all of the lobes of the brain, but even more profound neural connections to the parietal and frontal lobes; this interconnectivity suggests that the cerebellum may aid in the process of creative thinking (Vandervert, 2009, 2011). Indeed, a recent imaging study (fMRI) demonstrated that the cerebellum is involved in both the control of motor sequences and higherorder decision- and rule-making for the execution of any form of information from the prefrontal cortices, regardless of the abstractness of that information (Balsters et al., 2013).

\section{Occipital lobes}

Pearce et al. (2013) noted that Neandertal occipital lobes were larger than those of the AMH brain, a difference they speculated was related to the amount of light at different latitudes. Eye size, as measured by the orbital sockets, is related to the amount of visual cortex in living species. These authors surmised that Neandertals, being geographically distributed across more northerly latitudes, might have experienced and adapted to less light than the more equatorial $\mathrm{AMH}$; the increased occipital volume would have enabled Neandertals to discern visual details under conditions of poorer light. Increased occipital volume, however, also suggests a concomitant decrease in the relative volume of the other lobes, implying attendant differences in their cognitive functionality.

\section{Genetic evidence of cognitive differences}

An additional source of evidence for evolutionarily significant cognitive differences between Neandertals and AMHs comes from a comparison of their DNA. Non-synonymous substitutions (NSS) are genetic changes that result in phenotypic change, the very thing that natural selection acts upon. To date, several NSS between Neandertals and AMH have been found in genes implicated in cognitive functions such as learning and memory, representing a difference of nearly $10 \%$ with about a third of the Neandertal data unavailable for comparison (which means that additional differences may be found when the full dataset is analyzed; see Paixão-Côrtes et al., 2013). Even a single change to a single gene can profoundly affect the brain (Bakircioglu et al., 2011), and many of the NSS found to date affect genes implicated in learning and memory. Further, there is evidence for a positive selection for genes relating to olfaction in $\mathrm{AMH}$, well after 
the lineage split between the two human types (e.g., Bastir et al., 2011). Genetic data suggest that the two human types may have differed in learning, memory, and olfaction to an extent that would have been visible to selective forces, even if the differences were subtle. However, as Bruner \& Iriki (2015) note, the genetic evidence suggests one of several possible mechanisms for cognitive differences; the other mechanisms and influences on intra- and inter-specific evolutionary change are environmental, enhanced metaplasticity, and epigenetic.

Paleoneurology is not yet in a position to argue from gross differences in brain size and shape to specific differences in cognitive function, and may never be in such a position. However, differences in gross brain anatomy do imply that differences in cognitive function were almost certainly in place. Neandertal and AMH brains differed from one another in significant ways. AMH brains, especially, deviated from the typical primate and hominin pattern. It is not unreasonable to hypothesize that these differences had cognitive consequences. This is not a value judgment of good vs. bad, or better vs. worse; these is no need to erect a false dichotomy. Whatever their cognitive differences might have been, both species powered successful adaptations (Roebroeks \& Villa, 2011; Stewart, 2005). But today, only one survives, and it is appropriate to ask whether these cognitive differences might have played a role.

\section{The archaeological argument}

The archaeological signatures left behind by Neandertals and their contemporaries in Africa are actually very similar. On the level of basic adaptation they are indistinguishable: Both were prehistoric hunter-gatherers who relied on eclectic diets with varied mixes of local foods, employed prepared cored technologies to produce stone tools, and used composite tools and fire. Given these broad and significant similarities, it might be simplest to conclude that Neandertals' failure to prosper past about 30,000 years ago was a matter of bad luck, related perhaps to things like demographic change, resource availability, or disease. Yet the temporal coincidence of AMH expansion and Neandertal demise suggests that there may have been more to it, especially considering that all other archaic humans met a similar fate after encountering $\mathrm{AMH}$. Why did AMH prevail and all others fail? It may have been a matter of social group size and demographics. This is a reasonable hypothesis with some evidentiary support in the form of site sizes and numbers (Finlayson, 2009). But there were also brain differences that should not be ignored, differences that provide a strong prima facie case for a cognitive difference. It is certainly a viable hypothesis to test, and not an anachronistic hold-over from the days of Victorian exceptionalism, as Zilhão (2014) has contended.

But how can such a hypothesis be tested using archeological evidence? As just acknowledged, the archaeological signatures of Neandertals and their contemporaries are similar. But they are not identical, as all authorities would admit. These differences could be the result of different local culture-historic developments, or they could reflect different cognitive profiles. Separating the historical differences from the cognitive differences is not an easy task. Given the difficulty of the problem, what is perhaps the most discouraging fact of the debate is the haphazard approach taken by most protagonists. The debate has played out almost entirely at the level of descriptive data, without any formal framework for comparison.

\section{The trait list and its associated issues}

The default approach used, if not favored, by almost all archaeologists interested in the problem of the Neandertal demise is the trait list, despite the fact that this approach has repeatedly been found wanting (Henshilwood \& Dubreuil, 2011; Henshilwood \& Marean, 2003; Mellars et al., 2007; Nowell \& Davidson, 2010; Nowell, 2010; Wadley, 2003). As used by most protagonists in the debate (e.g., Villa \& Roebroeks, 2014), trait lists pose a number of serious problems:

1) Trait lists ignore equifinality. Multiple activities often produce the same archaeological 
signature, and only by careful analysis can they be discriminated. If they cannot be effectively discriminated, the rule of parsimony must be applied (i.e., opt for the explanation with the fewest assumptions). When considering cognition, this almost invariably requires favoring the simplest form of cognition that can account for the evidence.

2) Trait lists ignore both quantification and degree. If the archaeological record yields a thousand examples of an activity for one group but only one for the other, the trait list treats them as indistinguishable. Similarly, trait lists ignore the magnitude of expression in characterizing both a stick modified for termite fishing and a computer drive as 'tools'.

3) Trait lists ignore the context of the analyses from which the items are taken, including any cautions or caveats. If the persuasive power of an activity depends on the cooccurrence of other activities, this context vanishes from a trait list.

4) The activities on the list rarely have explicit theoretical justification. Most commonly, the elements on such lists accumulate over the decades and result from archaeological history and academic inertia.

5) Trait lists, especially in the case of those purporting to document 'modern' behavior, often include items that are not equivalent epistemologically. Villa \& Roebroeks' (2014) trait list, for example, included symbolism as one hypothesis and use of traps for another. The former is an inference, the latter a pattern of data.

The trait list of modernity has roots in European Palaeolithic archaeology that go back to the Victorian era mentioned by Zilháo (2014). Initially, the traits were those that distinguished the Aurignacian from the underlying Mousterian at sites such as La Ferrassie. Later, they came to be used as markers for a prehistoric invasion of Neandertal Europe by AMH. These traits were never selected with cognition in mind, but there certainly was an explicit tone of superior and inferior. This highlights the first serious problem with Villa \& Roebroeks' (2014) analysis: They retained the superior-inferior piece and ignored the cognitive vacuity. In defense of Villa $\&$ Roebroeks, one could argue that they compiled their list from the work of others and that any weaknesses reflected flaws in the reasoning of the original authors; Villa \& Roebroeks might simply then be seen as illustrating the folly of the approach. But their article did not appear to be intentionally ironic. Instead, Villa \& Roebroeks had a very specific claim to make concerning the fate of Neandertals - that the Neandertals were so indistinguishable from $\mathrm{AMH}$ that they were simply absorbed into the AMH population and thus Villa \& Roebroeks embraced the trait list as a valid method with a positive conclusion.

Even if archaeologists had a valid trait list in hand, a second problem would loom: what comparison should be made? Ideally, one would compare the Neandertal and AMH archaeological records at the same point in time, in similar environmental contexts. Two circumstances obviate any chance for such a comparison. $\mathrm{AMH}$ and Neandertals lived in very different environments, at least until AMH moved into Europe about 40,000 years ago. AMH were tropical and sub-tropical hunter-gatherers, while Neandertals were high-latitude and temperate hunter-gatherers. This difference alone should have produced significant differences in diet, if nothing else (Binford, 2001). Second, archaeologists actually know more about Neandertals than about their contemporaries, including contemporary $\mathrm{AMH}$. The African Middle Stone Age (MSA) is still poorly known when compared to the European Middle Palaeolithic. As a consequence, individual sites in Africa come to be compared to regional patterns in Europe. In such a comparison, the unusual can come to masquerade as the norm. More troubling, traits that are low in frequency at the best of times, but which are known from a few Neandertal sites, may not occur at all in the select MSA sites, biasing the comparison in favor of Neandertals. 


\section{Alternatives to the trait list}

One alternative would be to compare the extensive Neandertal record to a comparably extensive record of AMH living in the same environment. The best candidate for this comparison would be the European Gravettian, which is very well known in both Western and Central Europe. But such a comparison carries a bias for AMH. Being at least 10,000 years nearer the present, preservation would be better, especially for the perishable materials that have become so important to the comparison. In other words, taphonomy alone would bias the comparison, not to mention 10,000 years of culture change. Archaeologists are left, then, with a final alternative: the only documented example of Neandertals and AMH occupying the same environment at the same time - the Aurignacian colonization of Europe. Ironically, of course, this culture contact was precisely the motivation for the original trait list comparisons of the $19^{\text {th }}$ century.

However, there is a better way to compare than using trait lists: Rather than focusing on specific times and places hoping to get reliable 'flashbulb' images that provide reliable trait lists to compare, focus instead on a single behavioral/ cognitive domain, devise archaeologically visible criteria for recognizing it, and examine the archaeological traces from each group for evidence of how this domain fared over time. Here this approach will be briefly applied to two domains: first, the domain most commonly invoked in comparisons of Neandertals and AMH - symbolism - followed by the domain studied by Coolidge and Wynn for the last fifteen years, working-memory capacity.

Arguably, the most contentious false dichotomy in the Neandertal debate paints Neandertals as either non-symbolic or symbolically indistinguishable from AMH. This specific debate plays out almost entirely at the level of presence or absence of particular artifact types. What is almost shocking for a scholarly disagreement of this significance is the theoretical vacuity of most of this debate. Almost never does one encounter in-depth discussions of what a symbol is, what symbolism or symbolic culture are, or how these things might be recognized archaeologically. There are exceptions, of course. Twentyfive years ago, Davidson \& Noble (1989) used an informed discussion of iconicity to interpret the Palaeolithic record, and more recently Henshilwood \& Dubreuil (2009, 2011) used well-defined semiotic categories to interpret the beads from Blombos Cave in South Africa - but these are the exceptions. More often than not, authors devote the majority of their discussion to placing a particular artifact in time and association, and conclude that it constitutes evidence for 'symbolic culture' without engaging the far more difficult question of just what 'symbolic culture' means.

Did Neandertals have symbolic culture? Did they even use symbols? Answering these questions must begin with a generally accepted definition of symbol as something that 'stands for' something else via an arbitrary or conventionalized link (de Saussure, 1959; Peirce, 1932, 1991). Words are symbols, and some material objects are symbols (e.g., wedding rings). Zilhão (Zilhão et al., 2010) and d'Errico (d'Errico et al., $2003,2009)$ and others have convincingly established that Neandertals made pendants. Were these symbols? Among extant humans at least, personal ornaments are occasionally symbols, but more often they act as indexes. An index stands for something via association or direct extension (e.g., as smoke is an index of fire). When students attend university sporting multiple piercings with rings and bars and other ornamental paraphernalia, the objects are rarely symbolic, but they do mark perceived social identity. They are indexes. Thus, there are actually no grounds for concluding that Neandertal pendants were true symbols; rather, they were more likely to have been indexes of social identity. But is this not a kind of 'symbolic culture', using a more generous definition of symbolic culture as any use of material culture to send messages about identity? The answer is yes, but with this definition all examples of body marking would constitute evidence for symbolic culture, including the indirect evidence for body painting (via ground 
pigment) associated with $H$. heidelbergensis in both Europe and Africa (Barham, 2002; d'Errico et al., 2003).

Of course, the same critique can be - and has been - applied to AMH personal ornaments found in MSA contexts in Africa (Botha, 2008, 2010). Must it then be concluded that Neandertals and $\mathrm{AMH}$ are indistinguishable in this regard, as argued by Villa \& Roebroeks (2014), Zilhão (2014) and others? The parallel evidence for ornaments implies something very important, but it is not that Neandertals and AMH were indistinguishable. Rather, it indicates that one component of semiotic behavior - indexical marking - can be traced back to a common source in $H$. heidelbergensis, and that it is homologous for Neandertals and AMH. However, indexical usage also appears to have developed in rather different ways in the parallel lineages. When ornament use by Aurignacian people (again, the only justifiable comparison, as was earlier discussed) is compared to that of Neandertals, a large difference in quantity is apparent: The 10,000-year Aurignacian record has yielded thousands of beads and items of personal decoration, while the entire 200,000+ years of the Neandertal record has yielded fewer than 10 .

Even if the semiotic role - social marking - is held as having been the same, the actual way it developed in Aurignacian society must have been different from the way it did in Neandertal society. Aurignacian people appear to have been far more invested in social marking than Neandertals were. This difference suggests that Neandertal and $\mathrm{AMH}$ semiotic behavior developed along different trajectories since the time of their $H$. heidelbergensis common ancestor. They were similar but not identical. But was this difference a cognitive difference? Ironically, given the vituperative nature of the disagreement, the answer can only be "maybe." Indexical marking per se is not very challenging in a cognitive sense; it relies primarily on simple association. However, the vast difference in scale between Aurignacian index use and Neandertal index use suggests that there may have been a significant difference in social-information processing, and this points to the topic of working-memory capacity.
Coolidge and Wynn have written extensively about the role of enhanced working memory in recent human evolution (Coolidge \& Wynn, 2001, 2004, 2005, 2009; Wynn \& Coolidge, 2003, 2006, 2007, 2010a, 2010c, 2011), and they have also written specifically about Neandertal cognition in a separate set of publications (Wynn \& Coolidge, 2004, 2010b, 2012). Their initial argument concerning working memory was developed primarily as a general evolutionary model concerning modern human cognition (that is, it was not developed to contrast Neandertals and AMH, though incorrectly characterized as such by Villa $\&$ Roebroeks, 2014). The model was based on one of the most well-developed and thoroughly researched models of cognition in the psychological literature, Baddeley's model of working memory (Baddeley, 1994, 2000; Baddeley \& Hitch, 1974). This executive functions/working memory hypothesis has several features that make it a compelling hypothesis for recent cognitive evolution (Coolidge \& Wynn, 2001; Wynn \& Coolidge, 2010a):

1) The working-memory model is arguably the most successful and voluminously supported model of cognitive functioning developed in the last forty years.

2) The executive functions of working memory are implicated in the most sophisticated cognitive processing used by extant humans, including analogical reasoning, thought experimentation, contingency planning, levels of intentionality, and Theory of Mind.

3) Working-memory capacity varies in extant human populations.

4) Working-memory capacity and executive functions are both highly heritable, with estimates ranging from 77 to 99 percent (Coolidge et al., 2000, 2004; Friedman et al., 2008).

5) Working-memory capacity and executive functions are both under additive (polygenic) genetic control. Enhanced capacity could have been achieved via comparatively simple mutation, epigenetic change, or embodied resources of material culture (Overmann, 2013) in concert with neuronal recycling (Dehaene \& Cohen, 2007). 
The methodological challenge for Coolidge and Wynn was to identify archaeological patterns that might reflect an increase in working-memory capacity, something they termed enhanced working memory (EWM). As it turned out, no single artifact type or pattern could act as a reliable indicator for EWM (the closest to such a 'smoking gun' was the Hohlenstein-Stadel figurine), so instead, Coolidge and Wynn reviewed multiple possible lines of archaeological evidence. In the end, however, they argued that the archaeological record as it was then known was consistent with several alternative ways to understand the timing of the final enhancement of working-memory capacity, including one in which the final enhancement occurred very late indeed, after 30,000 years ago, and one in which it occurred 200,000 years ago. They did note that many of the archaeological patterns they chose to use as evidence for EWM were not apparent for Neandertals, but they also discussed at length how elusive they were for AMH. At about the same time that Coolidge and Wynn published the EWM hypothesis, they started to develop a model for Neandertal cognition that was also based on a well-developed set of theories in cognitive science (Wynn \& Coolidge, 2004, 2012). This particular model allowed them to account for the many similarities between the archaeological signatures of Neandertals and $\mathrm{AMH}$, and also understand the few differences.

One example of the kind of reasoning invoked in the working-memory hypothesis is the argument for use of traps. Coolidge \&Wynn (Coolidge \& Wynn, 2001, 2005, 2009; Wynn \& Coolidge, 2003, 2010a, 2011) emphasized the role of traps in managed foraging systems, their requirement for response inhibition (a well-defined, specific component of executive control), and their temporal range of planning. Unfortunately, evidence for use of traps is elusive; direct evidence of traps dates to no earlier than 14,000 years ago (Coolidge \& Wynn, 2005; Wynn \& Coolidge, 2003). As a consequence, arguments for earlier trap use necessarily rely on the indirect evidence of faunal remains - the presence of large numbers of a species that can only be effectively captured using traps. Wynn $\&$ Coolidge's initial review of the archaeological evidence yielded only a single example, one from Niah Cave in Borneo (Barker et al., 2007) that dated to between 42,000 and 28,000 years ago.

More recently, Wadley (2010) has made a similar argument for use of traps to capture blue duiker at Sibudu, with a much earlier date of perhaps 65,000 years ago. On its own, this indirect evidence for traps could not bear the weight of the EWM argument, so it was presented as one component among several, including use of fire to alter landscapes, which appeared about the same time at both Niah and in South Africa (Deacon, 1993). Use of managed foraging techniques implicated much longer projections of action into the future, as well as an important component of response inhibition. Both are components of executive reasoning. Coolidge and Wynn noted that these developments in managed foraging were paralleled by developments in technology, including the use of reliable weapon systems and the use of external calculating devices. Thus, the approach was not simply a number of checks off of a list, but rather an integrated model of cognitive evolution that concluded Neandertals and AMH were somewhat different.

The archaeological evidence - when interpreted as a component of an integrated model of cognitive evolution rather than through the problematic trait list technique - supports a picture of divergent lines of cognitive development for Neandertals and AMH. Working-memory capacity is something that evolved over the course of human evolution. Humans today have working memory, chimpanzees have working memory, and Neandertals had working memory. The archaeological evidence indicates that sometime after 100,000 years ago, AMH began to demonstrate behaviors that required a slightly larger working-memory capacity than anything known for Neandertals. It was not a dramatic difference, but it may have had profound, long-term consequences when people carrying Aurignacian culture colonized Europe beginning some 45,000 years ago. 


\section{The Neandertal fate: assimilation or replacement?}

Proponents of the Neandertal indistinguishability claim (e.g., Villa \& Roebroeks, 2014; Zilhão, 2014) have adopted it to support the idea of Neandertal assimilation, the hypothesis that the Neandertal disappearance from the archaeological record can be attributed to a wholesale incorporation and integration into the $\mathrm{AMH}$ population.. However, the assimilation hypothesis is challenged by the low percentage of Neandertal DNA in the human genome: only 1 to $4 \%$ of the genomes of Europeans and Asians; new evidence narrows the estimate to only $1.5-$ 2.1\% (Green et al., 2006; Prüfer et al., 2014). The low introgression rate, along with a skew in its directionality (i.e., from Neandertals to AMH but not the reverse), argues that interbreeding was rare, non-productive, or both (Currat \& Excoffier, 2011; Currat et al., 2008; Mason \& Short, 2011; Neves \& Serva, 2012). However, despite its low rate, introgression may have gained favorable alleles for $H$. sapiens, conferring adaptive fitness in systems interacting with new environments (Pääbo, 2015; Racimo et al., 2015; Weyer \& Pääbo, 2015).

While rare interbreeding seems the very opposite of assimilation, Neandertal indistinguishability proponents (Villa \& Roebroeks, 2014) have adopted non-productivity in an attempt to reconcile assimilation with the low introgression rate, citing mechanisms such as Haldane's rule, a form of reproductive isolation in which hybrid offspring, usually male, are viable but infertile (Mason \& Short, 2011). However, as Overmann \& Coolidge (2013) observed in their analysis of possible Neandertal-AMH reproductive isolating mechanisms, hybrid sterility has been estimated as taking an average of 2.0 to 4.0 million years to develop in mammals (Fitzpatrick, 2004; Wu, 1992), a span of time that is at least double and up to eight times the length of time separating the two human types (also see discussion in Gibbons, 2014). Could hybrid sterility have developed between Neandertals and AMH in that short a time span? While it seems less likely than the other forms of reproductive isolation typical among primates, if it is ultimately borne out by genetic evidence, it would mean that Neandertals and AMH accumulated significant differences as species in a very short amount of time, differences incompatible with the idea that the two were indistinguishable. That is, the genetic distance needed to produce hybrid sterility would entail morphological, behavioral, and cognitive differences - as can be observed in the case of horses and donkeys and their (almost invariably) infertile offspring, mules and hinnies (Rong et al., 1985, 1988; Vilà et al., 2001; Wu, 1992 ) - that would preclude the possibility that Neandertals and AMH were indistinguishable.

Neandertals and AMH differed in physical form and development, as many would agree (Gunz et al., 2010; Lieberman et al., 2007; Smith et al., 2010). Beyond their distinctive skulls, Neandertals were bigger, stockier, and had thicker bones (Ben-Itzhak et al., 2005). Their teeth differed, with Neandertals retaining archaic traits for larger, shovel-shaped incisors, while AMH developed smaller, chisel-shaped ones (Bailey, 2006; Bailey \& Liu, 2010; Le Cabec et al., 2013). The relative size and strength of bones and teeth, as well as the analysis of things like muscle attachments to bones and dental wear patterns, point to specific behavioral differences as well, with Neandertals thought to have led more strenuous lives (Berger \& Trinkaus, 1995; Bocherens, 2011; Gaudzinski-Windheuser \& Roebroeks, 2011; Knüsel, 2000) and to have made greater use of their anterior teeth as 'third hands' (Bruner \& Lozano, 2014; Overmann, 2015).

If Neandertals were morphologically, behaviorally, cognitively, genetically, and archaeologically different from AMH, as supported by the evidence reviewed here, they were not indistinguishable from $\mathrm{AMH}$, yet one interpretation of the genetic evidence suggests that the two human types interbred enough to leave a small but significant Neandertal component in the H. sapiens genome. However, an alternative interpretation of the genetic evidence suggests that instead of later interbreeding, it indicates an ancient population structure (Eriksson \& Manic, 2012) or 
admixture occurring prior to the divergence of the two human types (Gokcumen et al., 2013). If either of the alternative interpretations are ultimately borne out, it would mean that despite over 5,000 years of co-existence (Higham et al., 2011, 2014; Pinhasi et al., 2011), Neandertals and AMH likely did not interbreed, a finding that would further weaken the supportability of the assimilation and indistinguishability hypotheses.

\section{Conclusions}

The archaeological record is under constant scrutiny and reevaluation from new discoveries, emerging analytical techniques, and the application of inter-disciplinary insights. For example, newly discovered cave art has been attributed to Neandertals (Rodríguez-Vidal et al., 2014, though not without controversy; see Davidson, 2014), site chronologies and the period of Neandertal-AMH overlap is being substantiated (Galván et al., 2014; Higham et al., 2014; Wood et al., 2013), and paleoneurology continues to gain traction on the cognitive implications of the morphological and ontogenetic differences between Neandertal and AMH brains (Bruner, 2014). These avenues have the potential to inform and ultimately decide what really happened to the Neandertals and suggest that the archaeological approach most likely to yield an accurate account is one that embraces and integrates the work of other sciences.

The present review offered several sources of evidence as a basis for denying that Neandertals and $\mathrm{AMH}$ were indistinguishable. Must the alternative in the false dichotomy then be true - is the only other available viewpoint the one that considers Neandertals to be inferior to AMH? Such a view, unpalatable on its face, is not what we assert. The middle position being excluded by indistinguishability advocates (Villa \& Roebroeks, 2014; Zilhão, 2014) neither lumps nor splits the two human types but readily admits the large degree of overlap and characterizes the differences as subtle but visible to natural selection. It incorporates the paleontological, genetic, and archaeological data and proposes an interpretation that attempts to account for all the available data in a nuanced and balanced fashion.

Some have compared the Neandertal-AMH difference to extant human groups who differ in material culture, and have suggested that the middle position espoused here would inevitably assign extreme differences in modern material culture to different cognitive profiles. As the literature on cross-cultural cognition demonstrates, extant human groups differ subtly in ways related to material culture (e.g., Henrich et al., 2010). Yet, this hardly parallels the archaic argument, let alone affirms the false dichotomy. For one thing, such a result would be reached only if the comparison was theoretically vacuous, and based on simple checks on a list. Unlike Neandertals and $\mathrm{AMH}$, which are regarded as distinct species or subspecies (Bruner, 2013; Curnoe \& Thorne, 2003; Tattersall \& Schwartz, 1999; Wegmann \& Excoffier, 2010), extant humans are a single species with surprisingly little genetic variation, despite a misleading phenotypic variability (Ingman et al., 2000). This means extant humans all have the same cognition, even if that cognition varies slightly in interaction with different material-cultural situations. Further, it is that very ability to interact with a wide range of material conditions that may truly define extant humans as a species. In competition with the Neandertals, a species with a slightly different adaptation trajectory, AMH should be predicted to have expanded its range of material-cultural variability to the extent seen across the extant human population.

The main points of the argument in favor of the excluded-middle position - small differences that were significant because they were visible to natural selection - can be summarized as follows:

1) Neurocognition: Fossil skulls and endocasts clearly indicate that Neandertal and $\mathrm{AMH}$ brains differed in ways that have significant implications for cognitive functioning. In addition, archaic DNA indicates that the two human types differed in genes governing neurocognitive development in key cognitive functions like learning and memory. 
2) Archaeology: Comparisons based on checklists of traits for 'modern' behavior, like the one used by Villa and Roebroeks (2014), have long been identified as problematic and do not justify a finding of Neandertal indistinguishability. In comparison, models integrating archaeological with paleoneurological and genetic data suggest that Neandertals and AMH followed divergent cognitive trajectories that left subtle but detectible traces in the material record.

3) Genetic: If hybrid sterility is the correct explanation for the low rate and directionality of introgression between Neandertals and AMH, then the genetic distance entailed would preclude the two human types from being indistinguishable. If instead the archaic genome signals ancient population structure or admixture, then Neandertals did not assimilate.

Against the Neandertal indistinguishability claim, the converging evidence of multiple disciplines shows that AMH and Neandertal brains differed, their genes differed, their physiologies and behaviors differed, and their archaeological signatures differed. This evidence supports two conclusions: First, Neandertals and AMH differed cognitively; second, these cognitive differences may have played a role in the Neandertal disappearance from the archaeological record and the ultimate success of AMH. It is time, as Zilhão (2014) himself noted, to stop labeling differences as implying inferiority and superiority: This claim is not found in the extensive neuroscientific literature on archaic crania, paleoneurology, and cognitive evolution, so there is no reason to argue against it; claiming that it is being argued when it is not serves only to perpetuate the false dichotomy.

\section{Acknowledgements}

All three authors contributed equally to this work. We are grateful for the contributions of Dr. Emiliano Bruner and Dr. Giovanni Destro Bisol, whose close and critical review of the manuscript led to its significant improvement.

\section{References}

Addis D.R., Wong A.T. \& Schacter D.L. 2007. Remembering the past and imagining the future: common and distinct neural substrates during event construction and elaboration. Neuropsychologia, 45: 1363-1377.

Allen T.A. \& Fortin N.J. 2013. The evolution of episodic memory. Proc. Natl. Acad. Sci. USA, 110: 10379-10386.

Arsuaga J.L. 2001. The Neanderthal's Necklace: In Search of the First Thinkers. Four Walls Eight Windows, New York.

Azevedo F.A.C., Carvalho L.R.B., Grinberg L.T., Farfel J.M., Ferretti R.E.L., Leite R.E.P., Filho W.J., Lent R. \& Herculano-Houzel S. 2009. Equal numbers of neuronal and nonneuronal cells make the human brain an isometrically scaled-up primate brain. J. Comp. Neurology, 513: 532-541.

Baddeley A.D. 1994. The magical number seven: still magic after all these years? Psychol. Rev., 101: 353-356.

Baddeley A.D. 2000. The episodic buffer: a new component of working memory? Trends Cogn. Sci., 4: 417-423.

Baddeley A.D. \& Hitch G. 1974. Working memory. Psychol. Learn. Motiv., 8: 47-89.

Bailey S.E. 2006. Beyond shovel-shaped incisors: Neandertal dental morphology in a comparative context. Period. Biol., 108: 253-267.

Bailey S.E. \& Liu W. 2010. A comparative dental metrical and morphological analysis of a Middle Pleistocene hominin maxilla from Chaoxian (Chaohu), China. Quat. Int., 211: 14-23.

Bakircioglu M., Carvalho O.P., Khurshid M., Cox J.J., Tuysuz B., Barak T., Yilmaz S., Caglayan O., Dincer A., Nicholas A.K., Quarrell O., Springell K., Karbani G., Malik S., Gannon C., Sheridan E., Crosier M., Lisgo S.N., Lindsay S., Bilguvar K., Gergely F., Gunel M. \& Woods C.G. 2011. The essential role of centrosomal NDE1 in human cerebral cortex neurogenesis. Am. J. Hum. Genet., 88: 523-535.

Balsters J.H., Whelan C.D., Robertson I.H. \& Ramnani N. 2013. Cerebellum and cognition: evidence for the encoding of higher order rules. Cereb. Cortex, 23: 1433-1443. 
Barham L.S. 2002. Systematic pigment use in the Middle Pleistocene of South-Central Africa. Curr. Anthropol., 43: 181-190.

Barker G., Barton H., Bird M., Daly P., Datan I., Dykes A., Farr L., Gilbertson D., Harrisson B., Hunt C., Higham T., Kealhofer L., Krigbaum J., Lewis H., McLaren S., Paz V., Pike P., Piper P., Pyatt B., Rabett R., Reynolds T., Rose J., Rushworth G., Stephens S., Stringer C., Thompson J. \& Turney C. 2007. The "human revolution" in lowland tropical Southeast Asia: the antiquity and behavior of anatomically modern humans at Niah Cave (Sarawak, Borneo). J. Hum. Evol., 52: 243-261.

Bastir M., Rosas A., Gunz P., Peña-Melian A., Manzi G., Harvati K., Kruszynski R., Stringer C. \& Hublin J.-J. 2011. Evolution of the base of the brain in highly encephalized human species. Nat. Commun., 2: 1-8.

Bastir M., Rosas A., Lieberman D.E. \& O'Higgins P. 2008. Middle cranial fossa anatomy and the origin of modern humans. Anat. Record, 291: 130-140.

Bechara A., Tranel D. \& Damasio H. 2000. Characterization of the decision-making deficit of patients with ventromedial prefrontal cortex lesions. Brain, 123: 2189-2202.

Ben-Itzhak S., Smith P. \& Bloom R.A. 2005. Radiographic study of the humerus in Neandertals and Homo sapiens sapiens. Am. J. Phys. Anthropol., 77: 231-242.

Berger T.D. \& Trinkaus, E. 1995. Patterns of trauma among the Neandertals. J. Archaeol. Sci., 22: 841-852.

Binford L.R. 1981. Bones: Ancient Men and Modern Myths. Academic Press, New York.

Binford L.R. 2001. Constructing Frames of Reference: An AnalyticalMethod for Archaeological Theory Building Using Hunter-Gatherer and Environmental Data Sets. University of California Press, Berkeley.

Bocherens H. 2011. Diet and ecology of Neanderthals: implications from $\mathrm{C}$ and $\mathrm{N}$ isotopes: insights from bone and tooth biogeochemistry. In N.J. Conard \& J. Richter (eds): Neanderthal Lifeways, Subsistence and Technology: One Hundred Fifty Years of Neanderthal Study, pp. 73-86. Springer, Dordrecht.
Botha R. 2008. Prehistoric shell beads as a window on language evolution. Lang. Commun., 28: 197-212.

Botha R. 2010. On the soundness of inferring modern language from symbolic behaviour. Camb. Archaeol. J., 20: 345-356.

Bruner E. 2004. Geometric morphometrics and paleoneurology: brain shape evolution in the genus Homo. J. Hum. Evol., 47: 279-303.

Bruner E. 2010. Morphological differences in the parietal lobes within the human genus. Curr. Anthropol., 51: S77-S88.

Bruner E. 2013. The species concept as a cognitive tool for biological anthropology. Am. J. Primatol., 75: 10-15.

Bruner E. 2014. Functional craniology, human evolution, and anatomical constraints in the Neanderthal braincase. In T. Akazawa, N. Ogihara, H.C. Tanabe \& H. Terashima (eds): Dynamics of Learning in Neanderthals and Modern Humans: Cognitive and Physical Perspectives, vol. 2, pp. 121-129. Springer, Tokyo.

Bruner E., Amano H., de la Cuétara J.M. \& Ogihara N. 2015. The brain and the braincase: a spatial analysis on the midsagittal profile in adult humans. J. Anat., 227: 268-276.

Bruner E., de la Cuétara J.M., Masters M., Amano H. \& Ogihara N. 2014. Functional craniology and brain evolution: from paleontology to biomedicine. Frontiers in Neuroanatomy, 8: 1-6.

Bruner E. \& Iriki A. 2015. Extending mind, visuospatial integration, and the evolution of the parietal lobes in the human genus. Quatern. Int. (in press).

Bruner E. \& Lozano M. 2014. Extended mind and visuo-spatial integration: three hands for the Neandertal lineage. J. Anthropol. Sci., 92: 273-280.

Bruner E., Manzi G. \& Arsuaga J.L. 2003. Encephalization and allometric trajectories in the genus Homo: evidence from the Neandertal and modern lineages. Proc. Natl. Acad. Sci. USA, 100: 15335-15340.

Bruner E., Rangel de Lázaro G., de la Cuétara J.M., Martín-Loeches M., Colom R. \& Jacobs H.I.L. 2014. Midsagittal brain variation and 
MRI shape analysis of the precuneus in adult individuals. J. Anat., 224: 367-376.

Bruner E., Saracino B., Ricci F., Tafuri M., Passarello P. \& Manzi G. 2004. Midsagittal cranial shape variation in the genus Homo by geometric morphometrics. Coll. Antropol., 28: 99-112.

Cavanna A.E. \& Trimble M.R. 2006. The precuneus: a review of its functional anatomy and behavioural correlates. Brain, 129: 564-583.

Coolidge F.L. 2014. The exaptation of the parietal lobes in Homo sapiens. J. Anthropol. Sci., 92: 295-298.

Coolidge F.L. \& Overmann K.A. 2012. Numerosity, abstraction, and the emergence of symbolic thinking. Curr. Anthropol., 53: 204-225.

Coolidge F.L., Thede L.L. \& Jang K.L. 2004. Are personality disorders psychological manifestations of executive function deficits? Evidence from a twin study. Behav. Genet., 34: 73-82.

Coolidge F.L., Thede L.L. \& Young S.E. 2000. Heritability and the comorbidity of ADHD with behavioral disorders and executive function deficits: a preliminary investigation. Dev. Neuropsychol., 17: 273-287.

Coolidge F.L. \& Wynn T. 2001. Executive functions of the frontal lobes and the evolutionary ascendancy of Homo sapiens. Camb. Archaeol. J., 11: 255-260.

Coolidge F.L. \& Wynn T. 2004. A cognitive and neuropsychological perspective on the Châtelperronian. J. Anthropol. Res., 60: 55-73.

Coolidge F.L. \& Wynn T. 2005. Working memory, its executive functions, and the emergence of modern thinking. Camb. Archaeol. J., 15: 5-26.

Coolidge F.L. \& Wynn T. 2009. The Rise of Homo sapiens: The Evolution of Modern Thinking. Wiley-Blackwell, Oxford.

Curnoe D. \& Thorne A. 2003. Number of ancestral human species: a molecular perspective. Homo, 53: 201-224.

Currat M. \& Excoffier L. 2011. Strong reproductive isolation between humans and Neanderthals inferred from observed patterns of introgression. Proc. Natl. Acad. Sci. USA, 108: 15129-15134.
Currat M., Ruedi M., Petit R.J. \& Excoffier L. 2008. The hidden side of invasions: massive introgression by local genes. Evolution, 62: 1908-1920.

d'Errico F., Henshilwood C.S., Lawson G., Vanhaeren M., Tillier A.-M., Soressi M., Bresson F., Maureille B., Nowell A., Lakarra J., Backwell L. \& Julien M. 2003. Archaeological evidence for the emergence of language, symbolism, and music - an alternative multidisciplinary perspective. J. World Prehist., 17: 1-70.

d'Errico F., Vanhaeren M., Barton N., Bouzouggar A., Mienis H., Richter D., Hublin J.-J., McPherron S.P. \& Lozouet P. 2009. Additional evidence on the use of personal ornaments in the Middle Paleolithic of North Africa. Proc. Natl. Acad. Sci. USA, 106: 16051-16056.

d'Errico F., Zilhão J., Julien M., Baffier D. \& Pelegrin J. 1998. Neanderthal acculturation in Western Europe? A critical review of the evidence and its interpretation 1. Curr. Anthropol., 39: S1-S44.

Davidson I. 2014. Is that rock hashtag really the first evidence of Neanderthal art? The Conversation: Science + Technology. Retrieved September 10, 2014, from https://theconversation.com/is-that-rock-hashtag-really-the-firstevidence-of-neanderthal-art-31238

Davidson I. \& Noble W. 1989. The archaeology of perception: traces of depiction and language. Curr. Anthropol., 30: 125-155.

de Saussure F. 1959. Course in General Linguistics. The Philosophical Library, New York.

Deacon H.J. 1993. Planting an idea: an archaeology of Stone Age gatherers in South Africa. South African Archaeological Society, 48: 86-93.

Dehaene S. \& Cohen L. 2007. Cultural recycling of cortical maps. Neuron, 56: 384-398.

Eriksson A. \& Manic A. 2012. Effect of ancient population structure on the degree of polymorphism shared between modern human populations and ancient hominins. Proc. Natl. Acad. Sci. USA, 109: 13956-13960.

Finlayson C. 2009. Neanderthals and Modern Humans: An Ecological and Evolutionary Perspective, vol. 38. Cambridge University Press, New York. 
Fitzpatrick B.M. 2004. Rates of evolution of hybrid inviability in birds and mammals. Evolution, 58: 1865-1870.

Friedman N.P., Miyake A., Young S.E., DeFries, J.C., Corley R.P. \& Hewitt J.K. 2008. Individual differences in executive functions are almost entirely genetic in origin. J. Exper. Psychol., 137: 201-225.

Galván B., Hernández C.M., Mallol C., Mercier N., Sistiaga A. \& Soler V. 2014. New evidence of early Neanderthal disappearance in the Iberian Peninsula. J. Hum. Evol., 75: 16-27.

Gaudzinski-Windheuser S. \& Roebroeks W. 2011. On Neanderthal subsistence in last interglacial forested environments in Northern Europe. In N.J. Conard \& J. Richter (eds): Neanderthal Lifeways, Subsistence and Technology: One Hundred Fifty Years of Neanderthal Study, pp. 61-71. Springer, Dordrecht.

Gazzaninga M., Ivry R.B. \& Mangun G.R. 2013. Cognitive Neuroscience: The Biology of the Mind. $4^{\text {th }} e d$. W.W. Norton, New York.

Gibbons A. 2014. Neandertals and moderns made imperfect mates. Science, 343: 471-472.

Gibson K.R. 1991. Myelination and behavioral development: a comparative perspective on questions of neoteny, altriciality and intelligence. In K. R. Gibson \& A. C. Petersen (eds): Brain Maturation and Cognitive Development: Comparative and Cross-cultural Perspectives, pp. 29-63. Aldine Transaction, Piscataway, NJ.

Gibson K.R. \& Petersen A.C. 1991. Introduction. In K.R. Gibson \& A.C. Petersen (eds): Brain Maturation and Cognitive Development: Comparative and Cross-cultural Perspectives, pp. 3-12. Aldine Transaction, Piscataway, NJ.

Gokcumen O., Zhu Q., Mulder L.C.F., Iskow R.C., Austermann C., Scharer C.D., Raj T., Boss J.M., Sunyaev S., Price A., Stranger B., Simon V. \& Lee C. 2013. Balancing selection on a regulatory region exhibiting ancient variation that predates human-Neandertal divergence. PLoS Genet., 9: 1-12.

Green R.E., Krause J., Ptak S.E., Briggs A.W., Ronan M.T., Simons J.F., Du L., Egholm M., Rothberg J.M., Paunovic M. \& Pääbo S. 2006. Analysis of one million base pairs of Neanderthal DNA. Nature, 444: 330-336.
Gunz P., Neubauer S., Maureille B. \& Hublin J.-J. 2010. Brain development after birth differs between Neanderthals and modern humans. Curr. Biol., 20: R921-R922.

Harvey B.M., Klein B. P., Petridou N. \& Dumoulin S.O. 2013. Topographic representation of numerosity in the human parietal cortex. Science, 341: 1123-1126.

Henrich J., Heine S.J. \& Norenzayan A. 2010. The weirdest people in the world? Behav. Brain Sci., 33: 61-135.

Henshilwood C.S. \& Dubreuil B. 2009. Reading the artefacts: gleaning language skills from the Middle Stone Age in southern Africa. In R. Botha \& C. Knight (eds): The Cradle of Language, pp. 41-63. Oxford University Press, Oxford.

Henshilwood C.S. \& Dubreuil B. 2011. The Still Bay and Howiesons Poort, 77-59 ka: symbolic culture and the evolution of the mind during the African Middle Stone Age. Curr. Anthropol., 52: 361-400.

Henshilwood C.S. \& Marean C.W. 2003. The origin of modern human behavior. Curr. Anthropol., 44: 627-651.

Higham T.F.G., Compton T., Stringer C., Jacobi R., Shapiro B., Trinkaus E., Chandler C., Gröning F., Collins C., Hillson S., O’Higgins P., FitzGerald C. \& Fagan M. 2011. The earliest evidence for anatomically modern humans in northwestern Europe. Nature, 479: 521-524.

Higham T.F.G., Douka K., Wood R., Ramsey C.B., Brock F., Basell L., Camps M., Arrizabalaga A., Baena J., Barroso-Ruiz C., Bergman C., Boitard C., Boscato ., Caparros M., Conard N.J., Draily C., Froment A., Galvan B., Gambassini P., Garcia-Moreno A., Grimaldi S., Haesaerts P., Holt B., IriarteChiapusso M.-J., Jelinek A., Jorda Pardo J.F., Maillo-Fernandez J.-M., Marom A., Maroto J., Menendez M., Metz L., Morin E., Moroni A., Negrino F., Panagopoulou E., Peresani M., Pirson S., de la Rasilla M., Riel-Salvatore J., Ronchitelli A., Santamaria D., Semal P., Slimak L., Soler J., Soler N., Villaluenga A., Pinhasi R. \& Jacobi R. 2014. The timing and spatiotemporal patterning of Neanderthal disappearance. Nature, 512: 306-309. 
Hublin J.-J., Neubauer S. \& Gunz P. 2015. Brain ontogeny and life history in Pleistocene hominins. Philos. Trans. R. Soc. B, 370: 1-11.

Ingman M., Kaessmann H., Pääbo S. \& Gyllensten U. 2000. Mitochondrial genome variation and the origin of modern humans. Nature, 408: 708-713.

Kaas J.H. 2000. Why is brain size so important: design problems and solutions as neocortex gets bigger or smaller. Brain and Mind, 1: 7-23.

Knüsel C. 2000. Bone adaptation and its relationship to physical activity in the past. In M. Cox \& S. Mays (eds): Human Osteology: In Archaeology and Forensic Science, pp. 381-402. Cambridge University Press, Cambridge.

Koenigs M., Barbey A.K., Postle B.R. \& Grafman J. 2009. Superior parietal cortex is critical for the manipulation of information in working memory. J. Neuro. Sci., 29: 14980-14986.

Kubo D., Tanabe H.C., Kondo O., Ogihara N., Yogi A., Murayama S. \& Ishida H. 2014. Cerebellar size estimation from endocranial measurements: an evaluation based on MRI data. In T. Akazawa, N. Ogihara, H.C. Tanabe \& H. Terashima (eds): Dynamics of Learning in Neanderthals and Modern Humans: Cognitive and Physical Perspectives, vol. 2, pp. 209-215. Springer. Tokyo.

Land M.F. 2014. Do we have an internal model of the outside world? Philos. Trans. R. Soc. B, 369: 1-6.

Langbroek M. 2012. Trees and ladders: a critique of the theory of human cognitive and behavioural evolution in Palaeolithic archaeology. Quatern. Int., 270: 4-14.

Le Cabec A., Gunz P., Kupczik K., Braga J. \& Hublin J.-J. 2013. Anterior tooth root morphology and size in Neandertals: taxonomic and functional implications. J. Hum. Evol., 64: 169-193.

Lieberman D.E., Carlo J., Ponce de León M. \& Zollikofer C.P.E. 2007. A geometric morphometric analysis of heterochrony in the cranium of chimpanzees and bonobos. J. Hum. Evol., 52: 647-662.

Lou H.C., Luber B., Crupain M., Keenan J.P., Nowak M., Kjaer T.W., Sackeim H.A. \&
Lisanby S.H. 2004. Parietal cortex and representation of the mental Self. Proc. Natl. Acad. Sci. U.S.A., 101: 6827-6832.

Lübke K.T. \& Pause B.M. 2015. Always follow your nose: the functional significance of social chemosignals in human reproduction and survival. Horm. Behav., 68: 134-144.

Martin R.D. 1984. Body size, brain size and feeding strategies. In D. Chivers, B. Wood $\&$ A. Bilsborough (eds): Food Acquisition and Processing in Primates, pp. 73-103. Plenum Press, New York.

Mason P.H. \& Short R.V. 2011. Neanderthal-human hybrids. Hypothesis, 9: 1-5.

Mellars P., Boyle K., Bar-Yosef O. \& Stringer C. 2007. Rethinking the Human Revolution: New Behavioural and Biological Perspectives on the Origin and Dispersal of Modern Humans. McDonald Institute for Archaeological Research, Cambridge.

Mithen S. 2014. The cognition of Homo neanderthalensis and H. sapiens: does the use of pigment necessarily imply symbolic thought? In T. Akazawa, N. Ogihara, H.C. Tanabe \& H. Terashima (eds): Dynamics of Learning in Neanderthals and Modern Humans: Cognitive and Physical Perspectives, vol. 2, pp. 7-16. Springer, Tokyo.

Neves A.G.M. \& Serva M. 2012. Extremely rare interbreeding events can explain Neanderthal DNA in living humans. PLoS One, 7: 1-10.

Nowell A. 2010. Defining behavioral modernity in the context of Neandertal and anatomically modern human populations. Ann. Rev. Anthropol., 39: 437-452.

Nowell A. \& Davidson I. (eds) 2010. Stone Tools and the Evolution of Human Cognition. University of Colorado Press, Boulder.

Olson I.R., Ploaker A. \& Ezzyat Y. 2007. The enigmatic temporal pole: a review of findings on social and emotional processing. Brain, 130: 1718-1731.

Orban G.A. \& Caruana F. 2014. The neural basis of human tool use. Frontiers in Psychology, 5: 1-12.

Overmann K.A. 2013. Material scaffolds in numbers and time. Camb. Archaeol. J., 23: 19-39. 
Overmann K.A. 2015. Teeth, tools and human becoming. J. Anthropol. Sci., 93: 163-167.

Overmann K.A. \& Coolidge F.L. 2013. Human species and mating systems: NeandertalHomo sapiens reproductive isolation and the archaeological and fossil records. J. Anthropol. Sci., 91: 91-110.

Pääbo S. 2015. The diverse origins of the human gene pool. Nat. Rev. Genet., 16: 313-314.

Paixão-Côrtes V.R., Viscardi L.H., Salzano F.M., Bortolini M.C. \& Hünemeier T. 2013. The cognitive ability of extinct hominins: bringing down the hierarchy using genomic evidences. Am. J. Hum. Biol., 25: 702-705.

Pearce E., Stringer C. \& Dunbar R.I.M. 2013. New insights into differences in brain organization between Neanderthals and anatomically modern humans. Proc. R.. Soc. B Biol. Sci., 280: $1-7$.

Peirce C.S. 1932. Collected Papers of Charles Sanders Peirce, vol. 2. Harvard University Press, Cambridge, MA.

Peirce C.S. 1991. Peirce on Signs: Writings on Semiotic by Charles Sanders Peirce. University of North Carolina Press, Chapel Hill.

Pinhasi R., Higham T.F.G., Golovanova L.V \& Doronichev V.B. 2011. Revised age of late Neanderthal occupation and the end of the Middle Paleolithic in the northern Caucasus. Proc. Natl. Acad. Sci. USA, 108: 8611-8616.

Ponce de León M.S. \& Zollikofer C.P.E. 2001. Neanderthal cranial ontogeny and its implications for late hominid diversity. Nature, 412: 534-538.

Preuss U.W., Meisenzahl E.M., Frodl T., Zetzsche T., Holder J., Leinsinger G., Hegerl U., Hahn K. \& Müller H.J. 2002. Handedness and corpus callosum morphology. Psychiat. Res. Neuroim. 116: 33-42.

Prüfer K., Racimo F., Patterson N., Jay F., Sankararaman S., Sawyer S., Heinze A., Renaud G., Sudmant P.H., de Filippo C., Li H., Mallick S., Dannemann M., Fu Q., Kircher M., Kuhlwilm M., Lachmann M., Meyer M., Ongyerth M., Siebauer M., Theunert C., Tandon A., Moorjani P., Pickrell J., Mullikin J.C., Vohr S.H., Green R.E., Hellmann I.,
Johnson P.L.F., Blanche H., Cann H., Kitzman J.O., Shendure J., Eichler E.E., Lein E.S., Bakken T.E., Golovanova L.V., Doronichev V.B., Shunkov M.V., Derevianko A.P., Viola B., Slatkin M., Reich D., Kelso J. \& Pääbo S. 2014. The complete genome sequence of a Neanderthal from the Altai Mountains. Nature, 505: 43-49.

Racimo F., Sankararaman S., Nielsen R. \& Huerta-Sánchez E. 2015. Evidence for archaic adaptive introgression in humans. Nat. Rev. Genet., 16: 359-371.

Rightmire G.P. 2004. Brain size and encephalization in early to mid-Pleistocene Homo. Am. J. Phys. Anthropol., 124: 109-123.

Rilling J.K. \& Insel T.R. 1999. Differential expansion of neural projection systems in primate brain evolution. Neuroreport, 10: 1453-1459.

Rodríguez-Vidal J., d'Errico F., Pacheco F.G., Blasco R., Rosell J., Jennings R.P., Queffelec A., Finlayson G., Fa D.A., Gutiérrez López J.M., Carrión J.S., Negro J.J., Finlayson S., Cáceres L.M., Bernal M.A., Jiménez S.F. \& Finlayson C. 2014. A rock engraving made by Neanderthals in Gibraltar. Proc. Natl. Acad. Sci. USA, 111: 13301-13306.

Roebroeks W. \& Villa P. 2011. On the earliest evidence for habitual use of fire in Europe. Proc. Natl. Acad. Sci. USA, 108: 5209-5214.

Rong R.H., Cai H.D., Yang X. Q. \& Wei J. 1985. Fertile mule in China and her unusual foal. $J$. Roy. Soc. Med., 78: 821-825.

Rong R.H., Chandley A.C., Song J., McBeath S., Tan P.P., Bai Q. \& Speed R.M. 1988. A fertile mule and hinny in China. Cytogenet. Genome Res., 47: 134-139.

Sasaki C., Suzuki K., Mishima H. \& Kozawa Y. 2002. Age determination of the Dederiyeh 1 Neanderthal child using enamel cross-striations. In T. Akazawa \& S. Muhesen S. (eds): Neanderthal Burials: Excavations of the Dederiyeh Cave, Afrin, Syria. International Research Center for Japanese Studies, Kyoto, Japan.

Schacter D.L. \& Addis D.R. 2007. The cognitive neuroscience of constructive memory: Remembering the past and imagining the future. Philos. Trans. R. Soc. B, 362: 773-786. 
Shea J.J. 2003. Neandertals, competition, and the origin of modern human behavior in the Levant. Evol. Anthropol., 12: 173-187.

Smith T.M., Tafforeau P., Reid D.J., Pouech J., Lazzari V., Zermeno J.P., Guatelli-Steinberg D., Olejniczak A.J., Hoffman A., Radovčić J., Makaremi M., Toussaint M., Stringer C. \& Hublin J.-J. 2010. Dental evidence for ontogenetic differences between modern humans and Neanderthals. Proc. Natl. Acad. Sci. USA, 107: 20923-20928.

Stalnaker T.A., Cooch N.K. \& Schoenbaum G. 2015. What the orbitofrontal cortex does not do. Nat. Neurosci., 18: 620-627.

Stanyon R., Consigliere S. \& Morescalchi M.A. 1993. Cranial capacity in hominid evolution. Hum. Evol., 8: 205-216.

Stewart J.R. 2005. The ecology and adaptation of Neanderthals during the non-analogue environment of Oxygen Isotope Stage 3. Quat. Int., 137: 35-46.

Strous R.D. \& Shoenfeld Y. 2006. To smell the immune system: olfaction, autoimmunity and brain involvement. Autoimmun. Rev., 6: 54-60.

Tattersall I. \& Schwartz J.H. 1999. Hominids and hybrids: the place of Neanderthals in human evolution. Proc. Natl. Acad. Sci. USA, 96: 7117-7119.

Tulving E. 2002. Episodic memory: From mind to brain. Ann. Rev. Psychol., 53: 1-25.

Vandervert L.R. 2009. The appearance of the child prodigy 10,000 years ago: an evolutionary and developmental explanation. J. Mind Behav., 30: $15-32$.

Vandervert L.R. 2011. The evolution of language: the cerebro-cerebellar blending of visual-spatial working memory with vocalizations. J. Mind Behav. 32: 317-331.

Vilà C., Leonard J.A., Götherström A., Marklund S., Sandberg K., Lidén K., Wayne R.K. \& Ellegren H. 2001. Widespread origins of domestic horse lineages. Science, 291: 474-477.

Villa P. \& Roebroeks W. 2014. Neandertal demise: an archaeological analysis of the modern human superiority complex. PLoS One, 9: 1-10.

Wadley L. 2003. How some archaeologists recognize culturally modern behaviour: Reviews of current issues and research findings: human origins research in South Africa. S. Afr. J. Sci., 99: 247-250.

Wadley L. 2010. Were snares and traps used in the Middle Stone Age and does it matter? a review and a case study from Sibudu, South Africa. $J$. Hum. Evol., 58: 179-192.

Weaver A.H. 2005. Reciprocal evolution of the cerebellum and neocortex in fossil humans. Proc. Natl. Acad. Sci. USA, 102: 3576-3580.

Wegmann D. \& Excoffier L. 2010. Bayesian inference of the demographic history of chimpanzees. Mol. Biol. Evol., 27: 1425-1435.

Weyer S. \& Pääbo S. 2015. Functional analyses of transcription ractor binding sites that differ between present-day and archaic humans. Mol. Biol. Evol. (in press).

Wood R.E., Barroso-Ruíz C., Caparrós M., Pardo J.F.J., Galván Santos B. \& Higham T.F.G. 2013. Radiocarbon dating casts doubt on the late chronology of the Middle to Upper Palaeolithic transition in southern Iberia. Proc. Natl. Acad. Sci. USA, 110: 2781-2786.

Wu C.-I. 1992. A note on Haldane's rule: hybrid inviability versus hybrid sterility. Evolution, 46: 1584-1587.

Wynn T. \& Coolidge F.L. 2003. The role of working memory in the evolution of managed foraging. Before Farming, 2: 1-16.

Wynn T. \& Coolidge F.L. 2004. The expert Neandertal mind. J. Hum. Evol., 46: 467-487.

Wynn T. \& Coolidge F.L. 2006. The effect of enhanced working memory on language. J. Hum. Evol., 50: 230-231.

Wynn T. \& Coolidge F.L. 2007. Did a small but significant enhancement in working memory capacity power the evolution of modern thinking? In P. Mellars, K. Boyle, O.B. Yosef \& C. Stringer (eds): Rethinking the Human Revolution, pp. 79-90. McDonald Institute for Archaeological Research, Cambridge.

Wynn T. \& Coolidge F.L. 2010a. Beyond symbolism and language: an introduction to Supplement 1, Working Memory. Curr. Anthropol., 51: S5-S16.

Wynn T. \& Coolidge F.L. 2010b. How Levallois reduction is similar to, and not similar to, playing 
chess. In A. Nowel \& I. Davidson (eds): Stone Tools and the Evolution of Human Cognition, pp. 83-104. University of Colorado Press, Boulder.

Wynn T. \& Coolidge F.L. 2011. The implications of the working memory model for the evolution of modern cognition. Int. J. Evol. Biol., 2011: 1-12.

Wynn T. \& Coolidge F.L. 2012. How to think like a Neandertal. Oxford University Press, Oxford.

Wynn T. \& Coolidge F.L. (eds) 2010c. Working memory: beyond language and symbolism. Curr. Anthropol., 51: S1-S199.

Zilhão J. 2014. Neandertal-modern human contact in Western Eurasia: issues of dating, taxonomy, and cultural associations. In T. Akazawa, Y.
Nishiak \& K. Aoki (eds): Dynamics of Learning in Neanderthals and Modern Humans: Cultural Perspectives, vol. 1, pp. 21-57. Springer, Tokyo. Zilhão J., Angelucci D.E., Badal-García E., d'Errico F., Daniel F., Dayet L., Douka K., Higham T.F.G., Martínez-Sánchez M.J., Montes-Bernárdez R., Murcia-Mascarós S., Pérez-Sirvent C., Roldán-García C., Vanhaeren M., Villaverde V., Wood R. \& Zapata J. 2010. Symbolic use of marine shells and mineral pigments by Iberian Neandertals. Proc. Natl. Acad. Sci. USA., 107: 1023-1028.

Editor, Giovanni Destro Bisol 